This is a pre-copyedited, author-produced version of an article accepted for publication in Communication Theory following peer review. The version of record: Esa Reunanen, Risto Kunelius, The Transformation of Communicative Power Into Political Power, Communication Theory, Volume 30, Issue 1, February 2020 , Pages 1-20, is available online at: https://doi.org/10.1093/ct/qtz011

\title{
The transformation of communicative power into political power
}

\begin{abstract}
This article examines Jürgen Habermas' concept of communicative power and describes how it transforms into political power in actual decision-making. To do this, the article develops the use of Habermas' typology of validity claims in communicative action as a framework for analysis. This involves analyzing how public performances invoking these validity claims affect actors' "authority," which is then capitalized in policy-making. The article thus integrates Habermas' procedural view of deliberative politics with the more culturally oriented view of political performances. It also contributes to the discussion about the "mediatization of politics" by introducing a communicative perspective to complement the more common institutional and systems perspectives. This theoretical and analytical approach is illustrated by examples drawn from evidence in 16 semi-structured interviews conducted with participants in the policy networks involved in the 2015 Finnish labor market negotiations.
\end{abstract}

Keywords: communicative power, political performance, Habermas, mediatization of politics, governance 


\section{The transformation of communicative power into political power}

Normative and realist descriptions of democratic governance do not often coincide. Normative descriptions are mostly abstract. They formulate ideals against which it is possible to assess the quality of real political processes, making a claim for the importance and influence of shared democratic social imaginaries that can frame relations of power (e.g., Taylor, 2004). Realist descriptions, for their part, rely on notions of strategic and conflictual concepts of power that are devoid of such idealism. Whenever we think we see seemingly shared reason, realists claim, we should look at how it is framed and defined by hegemony and power (e.g., Bourdieu, 1998). This theoretical dichotomy helps identify the key ingredients of democratic imagination. At the same time, however, it builds an obstacle for enhancing a more nuanced analysis of how democracy actually works by reducing explanations to either pole of the dualism instead of urging us to concentrate on their interplay (Boltanski \& Thevénout, 2006; Dahlberg, 2014). ${ }^{1}$

One of the most influential attempts at overcoming this dichotomy of democratic theory is Jürgen Habermas’ Between Facts and Norms (1996). In this book, Habermas adopts the concept of communicative power from Hannah Arendt and uses it to bind his earlier normative ideas of deliberative democracy (Habermas, 1987, 1991) to a more sociologically valid and realistic description of political power. In a nutshell, for Habermas (1996), communicative power is a means of popular sovereignty, which counterbalances systemic forces like administrative and economic power. It stems from "shared beliefs" that are produced or reinforced "by the intersubjective recognition of a validity claim” (Habermas, 1996, p. 147). It thus differs from strategic or repressive power, understood as power “at the expense of others” (O’Mahony, 2010, p. 54). By appearing as a crosscutting counter-force for “autopoetic” systemic powers (e.g. Luhmann, 2012), communicative power remains critically connected to the realist yielding of power. By invoking "shared beliefs" or principles of argumentation as its resources, it mobilizes normative potentials. 
While theoretically elaborate, Habermas’ approach does not provide a compelling illustration of how - at the level of democratic practice - communicative power comes to influence administrative and economic powers and what kinds of effects it may have on the generation of binding political decisions. This reflects a more general shortage in the academic literature. As Herbst (2003, p. 488) notes, "we lack basic language to discuss authority, as understood by political theorists or sociologists, in its relation to political communication.”

In this article, we apply Habermas' well-known typology of validity claims (1996, p. 5) as a framework to capture the role of communicative power in actual decision-making. This means studying how political stakeholders negotiate their mutual relations with reference to performances that invoke the validity dimensions of (1) trust/suspicion (sincerity), (2) value commitments and justifications (rightness), and (3) knowledge, facts, and expertise (truth). We interpret the references to these validity dimensions as instances of authority performances that generate communicative power, which is then capitalized for actual policy-making. Thus, by looking at how policymakers make sense of each other's political performances and power resources and by analyzing how this sense-making relies on shared aspects of communicative action, we aim to show how normative communicative power intertwines with the more strategic aspects of political power. In other words, we examine how communicative power, generated in mediated public spheres, may transform into political power in actual decision-making.

The presence of the "public" as an environment of political decision-making connects our theoretical-analytical work to discussions about media power and the "mediatization of politics.” As the scholarly work on these issues has mostly started from an institutional perspective (Hjarvard, 2013; Kammer, 2013; Strömbäck \& Esser, 2014), there have also been suggestions for a systems theoretic perspective to better understand the general dynamics of mediatization in diverse and historically changing institutional settings (Kunelius \& Reunanen, 2012a, 2016; Marcinkowski \& Steiner, 2014). However, even these two perspectives together (institutional and systemic) omit 
something important. Systems require lifeworld resources to function, and the systems’ steering media (money, power, etc.) also need to be legitimized in lifeworld contexts (Habermas (1987). This brings in the communicative aspect of power. With the help of Habermas' concept of communicative power, we elaborate this third perspective and operationalize it for the empirical analysis of the mediatization of politics.

We do not try to evaluate the procedural "quality” of public opinion (Habermas, 1996, p. 362), neither do we seek to identify communication distortions of democratic governance, as a more normative reading of Habermas’ approach would suggest. Instead, we apply Habermas’ framework as a tool to analyze the power aspect of communicative power. While Forester (2003) shows that such analysis can be undertaken in a "line-by-line” ethnographic analysis of professional work conversations, we stay at a more general and illustrative level. Using 16 semi-structured interviews conducted with participants from the 2015 Finnish labor market negotiations as research material, we demonstrate our approach by analyzing how authority performances in the media affected the authority positions of participants in the policy networks involved in these negotiations. ${ }^{2}$

In what follows, we first situate the concept of communicative power into Habermas' more general conception of society, politics, and democracy and engage with some criticisms of this conception. Thereafter, we connect the concept with the idea of performative politics, suggested, for example, by Alexander (2011), Hajer (2009), and Kulynych (1997), and present our analytical typology of the three kinds of authority performances. In the empirical section, we flesh out the different authority performances by offering examples from the 2015 Finnish labor market negotiations, showing how different aspects of power/authority, which played out in media performances, transformed into power/authority in the policy networks. We conclude by summarizing the empirical findings and by evaluating the article's theoretical and methodological contributions. 


\section{Communicative power as a component of political power}

Habermas' conception of society builds on a broad division between the autonomous systems controlled by systemic logics and the lifeworld that refers to people's everyday naturallanguage-enabled interactions and communications. According to Habermas (1996, p. 39), “money and administrative power are systemic mechanisms of social integration that do not necessarily coordinate actions via the intentions of participants, but objectively, 'behind backs' of participants.” These social subsystems function according to their own steering media (e.g., money in the economic system) and control the resources at their disposal. This creates systemic powers that, in many ways, are necessary and useful for the functioning of society, but that can also have unwanted effects.

What Habermas adds to systems theory is an idea of communicative power that emanates from communicative action, which is, in turn, based on presuppositions inscribed in natural language. Habermas tries to save the normative ideal of popular sovereignty in theorizing the current complex and system-driven society. He $(1996,2006)$ presents a core-periphery model of deliberative politics, in which open debates in the public sphere (periphery) construct public opinions that are taken into account by authorized decision-making bodies (core). According to Habermas, public opinion creates influence that "is converted into political power when it affects the beliefs and decisions of authorized members of the political system and determines the behavior of voters, legislators, officials, and so forth” (1996, p. 363, emphasis in original).

As a concept, communicative power combines normative and empirical dimensions of politics. The word "communicative" refers to normative ideals of communicative action, while the word "power" refers to empirical potency in making a difference in actual decision-making. The normative roots of the concept derive from Hannah Arendt. Habermas contrasts Arendt's conception of power with that of Weber and states that "Arendt views power as the potential of 
common will formed in noncoercive communication” (1996, p. 147, emphasis in original). ${ }^{3}$ This formulation, of course, resonates well with Habermas’ own concept of communicative action, which is based on the idea that the use of natural language presupposes the possibility of mutual understanding and agreement. Habermas (1991) argues that human communication is ultimately impossible without an assumed shared orientation to the three implicit validity claims: truth, rightfulness, and truthfulness. In conversation, these claims are either accepted or questioned.

Habermas seems to use the term communicative power in two senses. First, it refers to a "motivating force of good reasons" and to the public use of communicative freedom "as a generator of power potentials” (1996, p. 147). Second, Habermas (1996, p. 371, emphasis in original) states that "public influence is transformed into communicative power only after it passes through the filters of institutionalized procedures of democratic opinion- and will-formation and enters through parliamentary debates into legitimate lawmaking.” Flynn (2004, p. 434) finds this use of the term inconsistent because "it is unclear whether communicative power amounts to discursive power produced through arguments within informal public spheres or is primarily associated with the institutional power to make binding decisions.” A simple answer to Flynn's problem is to read Habermas arguing that both options are right. In the public sphere, communicative power has to do with the motivational force of reasoned arguments that can generate power “potentials.” However, in interactions with decision-making networks and bodies, it may become a component of political power. Thus, through legislation, it transforms into a component of administrative power.

It is not always easy to grasp precisely how Habermas distinguishes among political, administrative, and social power. It seems that he understands political power as dependent on authorized positions in legislative processes and administrative power as dependent on authorized and bureaucratic positions in the implementation of legislation. Social power, for its part, is based on positions in society's other functional systems, most notably the economic system. What makes political power specific is that, by definition, it requires legitimation (Habermas, 2006). Other 
functional systems must consider this when seeking to have an impact on a political system, which also makes them partially dependent on the legitimation dynamics of the political system. This explains why interest and pressure groups put so much effort in rationalizing their functional interests in shared, mediated publicity, which is but one example of the mediatization of politics. Habermas’ model of deliberative politics has been a popular target of criticism, which we condense to three points. First, Habermas is criticized for his insufficient coverage of the productive aspect of power. In focusing on deliberative procedures, Habermas does not adequately analyze how (repressive) power is already inscribed in social structures and cultural identities (Fraser, 1990; Kulynych, 1997). Second, the very idea of rational deliberation can be seen as exclusive and ideological because the norm of rational deliberation is also contingent and political, and it discriminates against those who are not accustomed to the dominant repertoires of "rational-critical" argumentation (see Dahlberg, 2014, p. 27; Villa 1992, p. 715). The third criticism arises from an assumption that different political identities are based on different language games that cannot communicate with each other. Consensus is not possible, even in principle, and at best, democracy can be agonistic (Mouffe, 1999). These counter-arguments deserve a hearing before we move on to apply Habermas.

The first criticism can be somewhat rebutted with the fact that Habermas (1996, p. 321), indeed, acknowledges that social actors are "socialized in concrete forms of life, situated in historical time and social space," and "they must draw from resources supplied by their lifeworld and not under their control.” Deliberation is thus highly dependent on prevailing meanings, which leads to some voices being valorized over others and some others being marginalized (Dahlberg 2014). This, of course, is against the public sphere norm. The norm, however, is there especially to criticize prevailing conditions. In addition to this productive power of lifeworld contexts, Habermas also acknowledges the productive power of social subsystems. They coordinate action “"behind backs’ of participants” (Habermas 1996, p. 39). As Kulynych (1997, p. 318) rightly notes, 
Habermas - like Foucault - describes “a world where power is productive and dispersed and where political action is constrained and normalized.” They both describe a type of power that cannot be adequately characterized in terms of actors' intentions.

To the accusation that the differentiation between reasoned argumentation and coercion has itself ideological and exclusive character, “Habermasians” retort that democracy cannot avoid normative views of what is democratic and what is not, what is reasoned argumentation and what is coercion (Dahlberg, 2014, pp. 28-29). It is true that those who are accustomed to deliberative argumentation are in a better position than those who are not. However, Habermasians do not find fault in the deliberative norm, but in "the uneven distribution of sociocultural resources necessary for rational-critical deliberation” (Dahlberg, 2014, p. 29). Critical deliberation is a means of fighting against exclusions. Even the norm of deliberation itself is open to such criticism and correctives.

Regarding the third criticism, one can argue that even though different political identities are based on different values, meanings, and interests, they are not completely incompatible. The dogmas of each political group can be questioned from outside, which puts pressure on the group to rationally legitimize its position. Of course, there are interests and values that are axiomatic for a specific group, but even then, there is the possibility of rational discussion about the consequences of some decisions or about the fairness of a compromise. Rationalizing a radically different political identity and experience into the dominant language of reason may well narrow it down and distort its authentic claims, but by recognizing such positions, dominant forms of public reason make themselves vulnerable - for better or worse - to such challenges. One need only look at the progressive politics of identity or xenophobic forms of toxic populism - and the different theoretical positions that rationalize them - to see that this is the case.

The critical perspectives against the Habermasian model are important as they help point to the limits of what communicative power is or can be and how it can function. Thus, we understand communicative power as a communicative component of political influence/power that can 
intertwine with - but not normally overcome - the strategic components of political influence/power. Communicative power emanates from communicative action based on rational presuppositions (validity claims) inscribed in natural language and intersubjective reasoning. By orienting to the counter-factual ideal of communicative action, arguments can be criticized on the basis of these validity claims. We acknowledge that what dominates in real political discussions is the strategic action through which these validity claims are ignored, muted, or overplayed when actors orient to success. Strategic actors, however, cannot avoid (strategic or communicative) criticism in reference to the validity claims. Even when they strategically respond to this criticism, this response, again, becomes vulnerable to criticism in reference to the validity claims.

\section{Communicating political power: Authority performances based on validity claims}

The main interest in Habermas’ concept of communicative power has thus far been its normative aspect. However, in terms of the relevance of the concept, the power aspect is also essential. As stated earlier, we understand communicative power as one component in the influence that affects the political system. To the extent that communicative power (as a component of influence) is converted into political power, it also becomes a component of political power. With this talk about components, we stress that (as a potential grounded in contra-factuality) communicative power always exists alongside other forms of power. It is created in communicative action, which is - always, we would say - enmeshed with strategic action. As Habermas (1996, p. 323, emphasis in original) maintains, an ideal speech situation (pure communicative action) is "methodological fiction in order to obtain a foil against which the substratum of unavoidable social complexity becomes visible.” Perfect communication is distorted by “unequal distribution of attention, competence, and knowledge” as well as "egocentrism, weakness of will, irrationality, and self-deception” (1996, p. 325). In Habermas’ conception, it is also vulnerable to strategic 
manipulation and systemic coercion by "state and corporate interests and their instrumental media of money and power” (Dahlberg, 2014, p. 27).

Another less-developed aspect of the concept of communicative power is its connection to representation, rhetoric, and performance. Although Habermas has been somewhat suspicious about these aspects of communication (Peters, 1993), he accepts the idea that the public sphere should "not only detect and identify problems but also convincingly and influentially thematize them, furnish them with possible solutions, and dramatize them in such a way that they are taken up and dealt with parliamentary complexes” (Habermas, 1996, p. 359, emphasis added). This points to the unavoidable need to use rhetoric and performative tools in deliberative politics. For the analysis of communicative power, then, understanding the performative and representative sides of politics is essential. It is easy to agree with Hajer (2009, p. 50) that "an appreciation of the symbolic and the performative in politics is crucial to an understanding of how an authoritative governance is at all possible in an age of multiplicities.” By multiplicities, Hajer refers to the lack of a unified political center: there are multiple sites or arenas where politics is conducted; there is no coherent public; and there is a multiplicity of media. In this kind of environment, different actors frame issues differently, create counter-frames, and circulate competing narratives related to political issues, today also in communication networks that do not much overlap. Those symbolic and performative factors influence "what people accept from a government and what they accept as authoritative from those who (try to) govern” (Hajer, 2009, p. 50). Performances intertwine with strategic narratives (Jacobs \& Sobieraj, 2007; Miskimon, O’Loughlin \& Roselle, 2013) and interpretive frames (Entman, 1993; Gamson \& Lasch, 1983) and may strengthen or weaken the understanding of the situation suggested by each frame or narrative. To be viable, communicative power should survive in this kind of mediatized political environment (see Hjarvard 2013; Strömbäck \& Esser, 2014). 
Acknowledging the performative aspect of power, we will approach communicative power, which emerges from more or less implicit references, by means of the validity claims inherent in communicative action. According to Habermas (1991), these are truth, rightness, and sincerity. When involved in communication, we cannot but either confirm or doubt these implicit claims made by the speaker. We operationalize them to the respective typology of authority performances:

1. Knowledge: facts and expertise (truth)

2. Values: value commitments and justifications (rightness)

3. Trust: trust/suspicion, responsibility, loyalty (sincerity)

We understand political power as the medium of the political system that is located in the actor relations of policy networks where policy bargaining takes place. To operationalize ways in which communicative power emerges in these contexts, we have marginally renamed and reformulated the original validity claims. The most radical re-formulation is replacing (renaming) sincerity with trust and complementing this concept with assumed references to responsibility and loyalty. This makes sense because trust and sincerity are conceptually and logically connected; the question is whether A trusts B to be sincere. Responsibility and loyalty, for their part, emerge from our empirical research materials, the realities of policy networks. They can be interpreted as actors' implicit promises or commitments. The question, then, is whether other actors can trust the sincerity of these commitments. We have replaced the term rightness with values, but we retained Habermas' (1991) original meaning: rightness with respect to the normative context or that the norm itself is legitimate.

We use the terms power and authority on different levels. We mostly use authority to describe the characteristics or resources of individual actors (actual persons or organizations). We use power primarily to refer to power on a more abstract or general level. By performances, we 
simply mean the ways and repertoires with which actors present themselves and their arguments arguing for the positions or disputing performances of others - either directly to each other (network performance) or through the media (media performance). We acknowledge that performative action need not be "expressive" or "rational” in the sense that it would articulate one's views in an argumentative way. Instead, it may be disruptive in exposing the contingencies of the dominant discourses (Kulynych, 1997). We agree with Kulynych that even rational deliberations must somehow be performed, which is why they also necessarily contain performative elements (see also Alexander, 2011). However - and perhaps now thinking beyond Kulynych - we also believe that performative action always contains at least the potential for rational reflection, even if it is, in itself, agonistic and non-reasoning. Certainly, in order to become influential in consequential policy decision, performances need to be at least somehow spelled out, “rationalized.”

Although politics and the media are fundamentally intertwined (Hajer, 2009), different arenas and fields still have different rules regarding action. Decision-makers - at least in Finland seem to obey quite distinct rationalities when acting in policy networks and within media publicity (Reunanen, Kunelius \& Noppari, 2010; Vesa, 2015). Policy network rationality is based more on shared expert knowledge and transparent stakeholder interests, while media rationality builds more on simplified narratives and an emphasis on emotional and moral aspects of the issue. The success or failure of an actor's performances in the media does impact his or her position in policy networks, and it is possible to discern forms of authority that are at play both in media publicity and policy networks. However, these forms may render varying degrees of importance and differing interpretations in these two arenas. These remarks aid in identifying the theoretical object of our investigation. We are interested in how communicative power, built through media performances (articulating communicative validity claims), transforms into political power in policy networks. For mediatization research, this approach deepens the understanding of the media's arena function for politicians (see Van Aelst \& Walgrave, 2016) and proposes a new and shared analytical 
language that can potentially also capture the role of communicative elements of systemic policy network rationality.

Authority and power are relational concepts. Authority is dependent on and consists of recognition by others (Alasuutari, 2018). In policy networks, each participant’s authority thus depends on how other participants see it. From a systems theory perspective, authority/power can be understood as a fundamentally non-propositional and undifferentiated medium of politics - in Parsonian parlance, a generalized measure of different resources of power that an actor can mobilize. Policy networks, then, do not merely or even mostly function through exchange of resources, but also and crucially by mutual estimations of power. In order for these estimations to function, power and authority need to be communicated (Herbst, 2003; Kunelius \& Reunanen, 2012b). Thus, successful communication of power means that a powerful actor does not need to mobilize actual power resources.

The transformation of publicity-mediated political influence into political power in policy networks is a complex process. In the media arena, authority performances have multiple audiences, which may interpret them differently. For example, trade union leaders may appeal to moral principles (value-based authority performance) in public when opposing employers' suggestions to cut employee benefits. This may contribute to union leaders' value-based authority among union members. However, in policy networks, this may not affect union leaders’ value-based authority. Instead, it may contribute to their strategic authority because of their allegedly strengthened position among their constituents - as seen and evaluated by other political actors. Conversely, a powerful media performance of economic policy may support an actor's ideas in a policy network and, thus, increase his or her knowledge-based authority. 


\section{Legitimation and mandate: The impact of authority performances in policy networks}

We now turn towards illustrating these theoretical distinctions at the level of political practice. We ask what kind of impact can the communicative power generated in the public sphere have on the actual power play in policy networks and how can we trace this impact. We illuminate this by drawing from 16 semi-structured interviews with actors involved in the 2015 Finnish labormarket negotiations. The case focuses on a crucial moment of fundamental political contest over labor market issues in a globalized economic context. In 2015, instead of allowing labor market organizations to negotiate a collective agreement, the Finnish government set a precise, explicit goal that it then expected the labor market organizations to meet in order to increase Finland's competitiveness in the international market. ${ }^{4}$ This was something provocative in the country's corporatist tradition. The political tension was not only about arranging and facilitating a collective agreement; it was also a question about the future labor market negotiating system and the balance of power between politics (government), business (employer organizations), and labor (trade unions).

We understand the labor market negotiations as workings of several overlapping policy networks. Even though the actual negotiations were conducted among only seven central and national organizations, ${ }^{5}$ many other influential organizations and persons were involved. Among the most important were the government, the (central) Bank of Finland, the member associations of the Confederation of Finnish Industries (EK), the member unions of the central organizations of Finnish trade unions (SAK, STTK, and Akava), and the Federation of Finnish Enterprises. None of the parliamentary opposition parties had much involvement in the official negotiations, although some of their top figures were active in the policy networks in the case. This composition of participants in policy networks continues the corporatist and consensual tradition of Finnish economic policy (see, e.g., Rainio-Niemi, 2014). In recent years, this tradition has, however, been 
challenged with arguments that in the current global economic context, consensual decision-making is not sufficiently effective and that the government should assume clear responsibility for the policy reforms needed to secure the competitiveness of Finnish industries (see, e.g., Vihriälä, 2013). This was exactly what the three-party government sought to do. With this move, it challenged the inherited labor market tradition and raised the stakes in the negotiations - and complicated the element of 'trust' in the policy networks.

Of the interviewees, five represented labor organizations, four represented employer organizations, three represented civil servants in ministries, two represented political parties in government (1 member of parliament and 1 minister’s adviser), and two represented opposition political parties (2 members of parliament). All the interviewees were intensively involved in the case as specialists or leaders in their organizations. The interviews took place between October 2015 and January 2016 while the negotiation process was ongoing. In the interviews, we asked about the power balance between the participants in the case and the impact of the media in that balance. More specifically, we probed examples in which the media had described (a) who acts morally right or wrong, (b) who only pursues their own interest, (c) whose actions lead to intended targets, (d) who has the correct or accurate picture of the realities related to the debate, (e) who acts consistently and truthfully, and (f) who appears powerful. ${ }^{6}$ These open-ended themes produced a rich material from which we here present examples of how authority performances invoking truth, values, or trust seemed to impact on the power balance in policy networks.

As an overall conclusion, we wish to begin by saying that in policy networks, claims about immediate economic realities, i.e., knowledge performances, worked from a largely shared base, the interests of other stakeholders appeared transparent, and the values of each participant quite stable. On a longer time horizon, there surely have been communicative deliberations about the state of the national economy and considerations of fairness. However, in the actual negotiations, the strategic logic of conduct can be condensed into questions about (1) the power balance between the parties, 
(2) an acceptable compromise that would represent this power balance, and (3) making the details of the compromise as acceptable as possible for all partners involved.

In the mediated public sphere, the deliberations were clearly different. It was important for the parties in the negotiations to "sell" their agendas to their constituents. The negotiators of each party needed a mandate from their constituents, and this required authority performances in public. If they succeeded in legitimating their agenda, their mandate would be strong, which would strengthen their power position in policy networks.

In the old world, one could think that everything is dealt at the negotiating table, and there is not much that needs to be talked about in the media. In the current world, this would not work at all.... Especially on this trade union side, this is a citizen movement, and what is done has to have support from the citizens or the membership. Legitimation there among the people. On some metaphysical level, [legitimation] that nobody can exactly define. Such a feeling of legitimation. (Trade union executive)

Political leaders and experts are more or less dependent on the support of their constituents because constituents set the limits to their mandate. A strong mandate not only gives a leader a license to be tough in negotiations; it may also grant a license to capitulate or make compromises. A representative of an employer organization explained this well as he pondered about the targets of their media performances. The citation also exemplifies the relative (knowledge-based) consensus among parties about the economic situation. Knowledge-based authority performances were not needed among the negotiators, but they were crucial in the media in terms of convincing constituents about the matter. A labor union executive also confirmed this relative consensus between the negotiators as well as the tension with the constituents. 
They [trade union negotiators] surely know this [importance of competitiveness]. But that they can sell these things to their own constituents. I do not mean every lay member but something... This presupposes such publicity; it is via public discussion that the mindset of the labor movement can be affected. (Employer organization executive)

It is comforting that [the negotiators of employer organizations] have somewhat the same problem that we have, that their board is tough. It takes time to convince them, and it occasionally presents crazy expectations, just like ours. Thank God that they have this same problem, which enables us to ponder what would be accepted there and here and so on. (Trade union executive)

Negotiators require a mandate as well as legitimation from their boards, which, in turn, require a mandate and legitimation from their constituents. Communicative power comes into play in acts of convincing. Boards and their constituents have to be convinced that the agendas and resolutions are acceptable. In practice, this requires authority performances that not only serve each actor's systemic interests, but also invoke trust, values, and truth. They are rhetorical acts by which the parties construct their authority and try to stymie that of other parties. The performances often intertwine with strategic narratives and interpretive frames. However, they have communicative potential because by invoking claims about truth, values, and trust, they also inevitably become vulnerable to rational criticism that asks whether or not these validity claims are tenable. In what follows, we offer glimpses - based on our interviews - of this complex dynamic of communicative power in action. We show how the three types of authority performance (trust, values, and knowledge) were at play in the policy networks of the 2015 Finnish labor market negotiations. 


\section{Performing trust, values, and knowledge in the 2015 Finnish labor market negotiations}

Trust is about the characteristics of actors, especially about the relations among them. There are established rules about what is or is not acceptable. Short-term gains accrued though breaking such rules may hinder the long-term authority of an actor. For example, it is acceptable to bring out only the viewpoints that are favorable to one's aims and somewhat exaggerate the harms or benefits of some decisions when it seems strategically useful. Instead, purposeful bluffing and lying or driving some hidden agenda are detrimental to one’s trust-based authority in policy networks.

Giving wrong facts is fatal because it makes it impossible to build trust anymore. But a kind of delicate steering with information is probably an instrument everywhere. (Employer organization executive)

In the public, trust-related performances may be allegations of hidden agendas, such as the trade unionists' claim about the government's alleged ideological mission to ruin the traditional corporatist negotiation system by blackmailing and threatening the labor movement. The most important trust-related performances in the case, however, centered on the claim for responsibility. The participants wanted to appear to be responsible partners in trying to solve the problems in the economy and labor markets. It is bad for the actors’ trust-based authority - in policy networks and in public - if one selfishly refuses to compromise over a reasonable agreement. However, it is also bad for one's trust-based authority if one compromises too much and does not efficiently defend the interests of one's constituents. This contradiction has clearly been observed and negotiated in the Finnish labor market tradition. As the citation above suggests, strategic performances in the interest of constituents are accepted as long as there is no straightforward bluffing - a reasonable level of trustworthiness must be sustained. 
An example of the dynamic nature of communicative power and trust can be highlighted by looking at the summer of 2015, when the national negotiations failed because the Central Organization of Finnish Trade Unions (SAK) did not accept the government's preconditions regarding the negotiations. SAK was the only one of the three central labor organizations that did not accept the conditions set by the government, which led to negative trust-based authority performances against SAK, questioning SAK’s responsibility.

In a way, we were driven into a corner. We did not have a clear proposition of our own, and in the publicity and from the government's side, they questioned us about what SAK will do [regarding the competitiveness problem]. This pressure grew. (Trade union executive)

At this point, the government seemed confident in its own authority. It announced that it would find the means for reducing labor costs, even without the consent of the labor organizations. From SAK, the general social atmosphere demanded positive solutions to the competitiveness problem, not only a fight against the government. For this reason, SAK published its own proposal, which offered many tempting elements for employers. For example, SAK suggested that there would be no wage increase in 2017, and thereafter, the export sector would set the level of wage increase. This proposition was a powerful trust-based performance, through which SAK expressed its responsibility, in an effort to solve the competitiveness problem. This performance also challenged employers to return to the negotiating table. The proposal received a great deal of positive publicity, and there were questions as to why it was not good enough for the government. This performance clearly strengthened the labor movement's power position in the negotiations.

Values refer to widely shared ethical ideals such as fairness and equity. One typical valueargument - especially for the labor movement - was the idea of equity in negotiations: if employers 
receive some benefits at the expense of employees, the latter should receive compensation. The government along with the employers retorted that the agreement could not be equal in this simplistic sense because the aim was to lower employment costs and improve the competitiveness of Finnish companies. They argued that the agreement was, in the end, fair because better competitiveness would improve employment and support state finances, which is for the benefit of all - including those outside the labor market and union membership.

Another set of value-based authority performances accused the government's plans as unjust, disproportionate, and as targeting especially those in a weak position. These performances invoked values of justice and solidarity and succeeded in undermining the government's trust-based authority by presenting - despite its talk about the common good - the government's actions as unjust and oppressive.

I think that we succeeded pretty well [in our public communication] that if a person earns little more than two thousand euros a month, gross, from full-time work, then, is it justified to take away five percent of that? These arguments clearly worked for us. (Trade union executive)

Value-based authority performances seem to fit the media well because they can arouse emotions and resonate in the public discussion. In our labor market case, such performances were connected primarily to the government's plans to cut over time and Sunday work compensations, with low-paid workers, who also work on weekends, being hit the hardest. Especially influential was a television appearance of two midwives, who said that they understood the government's anxiety about competitiveness, but that they could not accept a solution that was stacked so heavily against low-paid shift workers. The midwives suggested that the government should cut holiday bonuses instead, which would treat different groups of workers more justly. The government considered this suggestion, found a way to accomplish it, and then changed its plans accordingly. 
The government thus skillfully turned this negative value performance of injustice into a positive value performance of justice - and an instance of government responsiveness.

Knowledge refers to the characteristics of reality and to the authority of knowing how things are. Thus, the agenda and performance of a politician can be seriously questioned by showing that it is based on erroneous background information. Convincing expertise confers authority in the design of political solutions. In our case study, the most important knowledge-based performances concerned the economic situation, especially analyses of the alleged problems regarding the competitiveness of Finnish enterprises. Another key theme was the question about expertise in the labor market. The labor organizations, in particular, tried to improve their authority by performing as experts in the field and accusing the government of incompetence.

The power of knowledge-based performances was apparent in the summer of 2015 when the government and employers succeeded in creating public pressure that forced the trade unions to the negotiating table, even though more than a year remained before the expiration of the earlier general agreements. Their knowledge-based performances generated a sense of crisis among the members of the trade unions, which urged the union leaders to find solutions to the competitiveness problem and allowed them a mandate to agree and make compromises.

Successful promoting of issues includes - maybe in chronological order - that one [first] creates pressure through the media and [through] some other [channels]; a kind of pressure that comes from public debate, a political pressure, one can say. Then, in the second phase, induced by that pressure, the negotiations are started, the proposal for the negotiations is introduced, and a situation is created whereby an agreement must be achieved. It can be said that the employers have now acted exactly in this way. The competitiveness issue has been created - yet competitiveness is a genuine problem; it is not only created in the media, it is real. But in any case, there has been 
that plugging about the importance of improving competitiveness. And the government has been involved really heavily. And the negotiating table has now been opened. Let's see if anything will come out of there. But it is the case that in the current world, the pressure created in the media is an essential part of the successful promotion of issues. (Trade union executive)

It would have been difficult for the labor movement to abstain in the negotiations suggested by the government because the competitiveness problem seemed valid. Abstaining would have deteriorated the labor movement's trust-based authority. In the autumn, however, SAK's own proposal and the government's legislative proposals changed the situation. The government's proposals were vulnerable to knowledge-based criticism, and SAK's proposal seemed better argued.

That balance changed somewhat in September when we introduced SAK's own paper. We also started to get support from clearly right-wing economists or former EK leaders; statements published in newspapers that it was a good paper and it should be put into action. (Trade union executive)

The government's numerous instances of backing away from its objectives and changing its plans also evoked suspicions about deficits in the government's expertise, which clearly deteriorated its knowledge-based authority. This also affected the employer organizations’ assessment of the situation. They could not trust in the government's ability to put its plans into action as much as they did in the summer. Second, SAK's proposal had increased both knowledge and trust-based pressures to take part in the negotiations again.

It is important to note that in policy networks, knowledge contributes to authority, even without public performances. Knowledgeable people are listened to, and their arguments have 
weight. The working group that prepared the legislation aimed at reducing labor costs is a good example here. Representatives of the employer and employee organizations took part in this group and were able to have an impact on the details of the legislation, even though their role was only consultative.

They [representatives of labor organizations] can take part in these working groups constructively, even though they say all the time that "we don't accept this and we shall make a statement of disagreement, but let's think over what would be the best way to do this within your parameters.” (Minister’s adviser)

Knowledge claims seem to have a somewhat special position in the competition for communicative power. Knowledge seemed to be the only authority mode with a capacity to affect all other authority modes. For example, the value-based performances about equity and fairness between employers and employees were challenged by knowledge-based performances about how favoring employers can, in the long run, bring about universal benefit. Knowledge-based performances can also support or discredit trust. For example, the criticism against the government's legislative proposals deteriorated both the trust- and knowledge-based authority of the government. Knowledge performances can be ignored, and on the basis of the same knowledge, it is possible to make different value-based choices. However, knowledge enables one to see how different values can be attained and what kinds of consequences different value-based decisions may have. Values and trust are more or less negotiable, but knowledge that is known to be true cannot be agreed to be something else. Knowledge-based authority, however, is weakened by the fact that especially in complex issues - what political issues usually are - knowledge is uncertain and leaves room for doubt and alternative understandings. 


\section{Conclusion}

In this article, we have opened up Habermas' concept of communicative power in order to focus on its power aspect and to ask what kind of impact communicative power may have in actual decision-making (political power). From the point of view of political theory, bridging the concepts of communicative power and political power offers a way to navigate between the reductionism of a power-focused realism and abstract normative democratic ideals. By taking seriously the notion that power depends on its (strategic and communicative) communication, we operationalized communicative power as authority performances in order to identify ways in which political actors try to handle the critical, rational resistance of those whom they aim to convince. This offers a useful language for analyzing authority both in policy networks (network performances) and in the media (media performances).

In the field of mediatization research, approaching the media as a particular (and changing) arena for knowledge, value, and trust performances raises new, more nuanced questions about the dynamics of the relationship between media and politics and the performative aspects of this relationship. It deepens our understanding of the media's function as an arena for politicians and explains how policy networks are shaped not only by the exchange of resources but also by changing mutual estimations of these resources and the shifting situations in which they can - or cannot - be easily mobilized. Authority performances in the media seem to affect these situations and on the resource estimations as well. Overall, our analysis thus suggests that influence created in the public sphere does transform into political power in policy networks and it also illuminates how this happens.

Our empirical conclusions, of course, are only tentative and are aimed mainly at illustrating the theoretical and analytical points presented here. However, we still believe that these findings are real and that they highlight patterns in the media-politics relationship that can be generalized 
beyond this (quite specific) case. The validity criteria of trust, values, and knowledge are always somehow in play when political actors negotiate their legitimacy and authority. In different political cases and different political systems, these criteria may be implemented differently. However, at least in viable liberal democracies, we believe that these criteria are powerful categories that parties use to establish their authority in different phases of the political drama. Indeed, the various visible articulations of trust, values, and knowledge in authority performances might be understood to indicate a shared democratic context that all actors recognize. In our example, the government favored knowledge-based performances when legitimizing its actions to reduce labor costs, while the labor movement favored trust-based performances when accusing the government of blackmail and when responding to claims for positive solutions with its own proposal.

Finally, developing an analytical language anchored in the theory of communicative action can help us to come to terms with and make use of the inherent, persistent normative undertones of the mediatization debate. While we agree with Landerer (2013) that sweeping judgements of “media logic" should be avoided, this does not mean that more nuanced tools for thinking about how to assess the role of the media as an environment for democratic politics are not needed. This is why we believe that it is crucial to develop links between discussions about media power on one hand and theories about public debate and the role of reasonable, rational discourse in political decision-making on the other. In the end, such work may help us determine which aspects of media and publicity actually serve open, responsive democracy - and which do not. 


\section{References}

Alasuutari, P. (2018). Authority as epistemic capital. Journal of Political Power, 11(2), 165-190. doi:10.1080/2158379X.2018.1468151

Alexander, J. C. (2011). Performance and power. Cambridge: Polity.

Boltanski, L., \& Thevénout, L. (2006). On justification. Economies of worth. Princeton and Oxford: Princeton University Press.

Bourdieu, P. (1998). Practical reason. On the theory of action. Stanford: University of Stanford Press.

Compston, H. (2009). Networks, resources, political strategy and climate policy. Environmental Politics, 18(5), 727-746. doi:10.1080/09644010903157032.

Dahlberg, L. (2014). The Habermasian public sphere and exclusion: An engagement with poststructuralist-influenced critics. Communication Theory, 24(1), 21-41. doi:10.1111/comt.12010.

Entman, R. M. (1993). Framing: Toward clarification of a fractured paradigm. Journal of Communication, 43(4), 51-58. doi:10.1111/j.1460-2466.1993.tb01304.x

Flynn, J. (2004). Communicative power in Habermas's theory of democracy. European Journal of Political Theory, 3(4), 433-454. doi:10.1177/1474885104045914

Forester, J. (2003). On fieldwork in a Habermasian way: Critical ethnography and the extraordinary character of ordinary professional work. In M. Alvesson \& H. Willmott (Eds.), Studying management critically (pp. 46-65). London: Sage. doi:10.4135/9781446220030.n3

Fraser, N. (1990). Rethinking the public sphere: A contribution to the critique of actually existing democracy. Social Text, 25/26, 56-80. doi:10.2307/466240

Gamson, W. A., \& Lasch, K. E. (1983). The political culture of social welfare policy. In S. E. Spiro (Ed.), Evaluating the welfare state. Social and political perspectives (pp. 397-415). New York: Academic Press. doi:10.1016/B978-0-12-657980-2.50032-2 
Habermas, J. (1987). The theory of communicative action. Vol 2. Lifeworld and system: A critique of functionalist reason. (T. McCarthy, Trans.). Boston, MA: Beacon Press.

Habermas, J. (1991). The theory of communicative action. Vol 1. Reason and the rationalization of society. (T. McCarthy, Trans.). Cambridge: Polity Press.

Habermas, J. (1996). Between facts and norms: Contributions to discourse theory of law and democracy. (W. Rehg, Trans.). Cambridge: Polity Press \& Oxford: Blackwell Publishers Ltd.

Habermas, J. (2006). Political communication in media society: Does democracy still enjoy an epistemic dimension? The impact of normative theory on empirical research. Communication Theory, 16(4), 411-426. doi:10.1111/j.1468-2885.2006.00280.x

Hajer, M. A. (2009). Authoritative governance: Policy-making in the age of mediatization. Oxford: Oxford University Press.

Herbst, S. (2003). Political authority in a mediated age. Theory and Society, 32(4), 481-503.

Hjarvard, S. (2013). The mediatization of society and culture. London: Routledge.

Jacobs, R. N., \& Sobieraj, S. (2007). Narrative and legitimacy: US congressional debates about the nonprofit sector. Sociological Theory, 25(1), 1-25. doi:10.1111/j.1467-9558.2007.00295.x

Kammer, A. (2013). The mediatization of journalism. MedieKultur, 29(54), 141-158. doi:10.7146/mediekultur.v29i54.17385

Kulynych, J. J. (1997). Performing politics: Foucault, Habermas and post-modern participation. Polity, 30(2), 315-346.

Kunelius, R., \& Reunanen, E. (2012a). The medium of the media: Journalism, politics and the theory of “mediatization.” Javnost - The Public, 19(4), 5-24. doi: 10.1080/13183222.2012.11009093 
Kunelius, R., \& Reunanen, E. (2012b). Media in political power: A Parsonian view on the differentiated mediatization of Finnish decision makers. The International Journal of Press/Politics 17(1), 56-75. doi:10.1177/1940161211424207.

Kunelius, R., \& Reunanen, E. (2016). Changing power of journalism: The two phases of mediatization. Communication Theory, 26(4), 369-388. doi:10.1111/comt.12098.

Landerer, N. (2013). Rethinking the logics: A conceptual framework for the mediatization of politics. Communication Theory, 23(3), 239-258. doi:10.1111/comt.12013.

Luhmann, N. (2012). Theory of society. Volume 1. (R. Barrett, Trans.). Stanford, CA: Stanford University Press.

Marcinkowski, F., \& Steiner, A. (2014). Mediatization and political autonomy - A systems approach. In F. Esser \& J. Strömbäck (Eds.), Mediatization of politics: Understanding the transformation of western democracies (pp. 74-89). Basingstoke: Palgrave Macmillan. doi:10.1057/9781137275844_5

Miskimon, A., O’Loughlin, B., \& Roselle, L (2013). Strategic narratives: Communication power and the new world order. New York: Routledge.

Mouffe, C. (1999). Deliberative democracy or agonistic pluralism? Social Research, 66(3), 745758.

O’Mahony, P. (2010). Habermas and communicative power. Journal of Power, 3(1), 53-73. doi:10.1080/17540291003630361

Peters, J. D. (1993). Distrust of representation: Habermas on the public sphere. Media, Culture and Society, 15(4), 541-571. doi:10.1177/016344393015004003

Rainio-Niemi, J. (2014). A Nordic paradox of openness and consensus? The case of Finland. In N. Götz \& C. Marklund (Eds.), The paradox of openness: Transparency and participation in Nordic cultures of consensus (pp. 27-49). Leiden: Brill. doi:10.1163/9789004281196_004. 
Reunanen, E., Kunelius, R., \& Noppari, E. (2010) Mediatization in context: Consensus culture, media and decision making in the $21^{\text {st }}$ century, the case of Finland. Communications: The European Journal of Communication Research, 35(3), 287-307. doi: 10.1515/comm.2010.016

Smith, M. J. (1993). Pressure, power, and policy: State autonomy and policy networks in Britain and the United States. New York: Harvester Wheatsheaf.

Strömbäck, J., \& Esser, F. (2014). Mediatization of politics: Towards a theoretical framework. In F. Esser \& J. Strömbäck (Eds.), Mediatization of politics: Understanding the transformation of western democracies (pp. 3-28). Houndmills: Palgrave. doi:10.1057/9781137275844_1

Taylor, C. (2004). Modern social imaginaries. Durham \& London: Duke University Press.

Van Aelst, P., \& Walgrave, S. (2016). Information and arena: The dual function of the news media for political elites. Journal of Communication 66(3), 496-518. doi:10.1111/jcom.12229

Vesa, J. (2015). Nordic openness in practice: Loose coupling of government communication and policy making in Finland. Nordicom Review, 36(2), 129-142. doi:10.1515/nor-2015-0021

Vihriälä, V. (2013). Konsensuksen kuolema? - Perinteinen kolmikanta ei enää toimi, miksi ja mitä tilalle [The death of consensus?]. Helsinki: EVA.

Villa, D. R. (1992). Postmodernism and the public sphere. The American Political Science Review, 86(3), 712-721. doi:10.2307/1964133 


\section{Notes}

\footnotetext{
${ }^{1}$ This is not to deny the value of theoretical and empirical contributions made in the "realist" and "normative" schools of thought.

${ }^{2}$ Policy networks consist of actors who have an interest in and take part in policy processes. The cooperation of actors is largely motivated by their mutual dependency (see Compston, 2009; Smith, 1993). The concept of authority performance highlights the potential of political/public performances to demonstrate and establish authority in the public sphere; this potential can be transferred to authority positions in policy networks. One act of political communication can be at the same time a public, political, and authority performance. The term public performance highlights its public (often mediated) aspect, political performance its political aspect (politicizing issues, making substantial claims), and authority performance its potential to affect the performer's power position.

${ }^{3}$ For a critical analysis of Habermas' interpretation of Arendt, see Villa (1992).

${ }^{4}$ Following the parliamentary elections in April 2015, the new government comprised of the moderate conservative Center Party, the liberal democratic Coalition Party, and the conservative nationalist Finns Party. The Social Democratic Party was the largest party in opposition. In its program, the new government proposed a "(new) social contract" to reduce unit labor costs by at least $5 \%$. It expected the "social partners" (labor organizations) to commit comprehensively to the social contract by 21 August 2015, otherwise enacting the optional reductions and tax increases it had decided.

${ }^{5}$ The three central Finnish trade union organizations (SAK, STTK, and Akava), The Confederation of Finnish Industries (EK), and the three organizations representing public employers (Office for the Government as Employer, Local Government Employers, and Office for the Church as Employer).

${ }^{6}$ We also asked about the overall situation of the case as well as the interviewees' contacts and cooperative networks. The formulation of questions varied somewhat, and not all questions were asked in all the interviews. The average length of the interviews was 83 minutes. The interviews were conducted in Finnish while the negotiations still ongoing. All quotations have been translated by the authors. The interviewees were assured of anonymity to free them to comment on potentially delicate issues. Our impression was that they were quite open regarding issues relevant to this study while taking care not to disclose confidential information about the parties' substantive positions in the negotiations. All the interviewees are well connected in policy networks related to labor market negotiations and many of them have decades of experience in the field.
} 